\title{
Erectile dysfunction - the old and the new
}

\author{
Ajith P Malalasekera \\ Department of Anatomy, Faculty of Medicine, University of Colombo
}

\begin{abstract}
Key words: Erectile dysfunction; endothelial dysfunction; 5-phosphodiesterase inhibitors; penile prostheses
\end{abstract}

\begin{abstract}
Introduction
Impotence or erectile dysfunction (ED) has been recognised as a disease with various treatments attempted from ancient times. Emperor Shen-Nung, a Chinese mythical emperor (3500-2600 BCE) apparently recommended the use of ginseng in the treatment of ED and for stimulating sexual appetite[1]. In the modern era, erectile dysfunction (ED) has come a long way from being classified purely as a psychiatric disorder. The giant strides achieved due to a better understanding of its pathophysiology; the Nobel prize winning discovery of the nitric oxide/cyclic GMP pathway facilitating the development of 5 phosphodiesterase inhibitors; the invention of penile prosthesis dating way back to the 1960s, have revolutionised the understanding and management of this very sensitive problem. However, erectile dysfunction still remains a problem that is unfortunately closeted within the bedroom. This is despite attempts to deshroud the problem and motivate healthcare workers to include it within the day to day history taking practice. This is bound to be more so in conservative cultures such as in Sri Lanka.
\end{abstract}

\section{Epidemiology}

The prevalence of ED in American men between the ages of 40-70 years is $52 \%$, according to the Massachusetts male ageing study. This includes $10 \%$ with complete ED and $25 \%$ with moderate ED. This is a significant public health issue and is bound to rise with the increase in the ageing population and the worldwide increase in body weight and the incidence of diabetes [2]. There is no epidemiological data of those with ED in the Sri Lankan setting. However, a UK study, comparing prevalence of ED among those of European origin versus South Asians, including

Correspondence :

Malalasekera AP

Email : ajithpm@yahoo.com
Sinhala and Tamil speaking individuals, showed no statistically significant difference [3]. While there are obvious differences in lifestyle and other factors relating to ED in a Sri Lankan population residing in the UK versus in Sri Lanka, factors such as the rising incidence of diabetes in the Asian subcontinent, unhealthy dietary habits and exercise patterns make it reasonable to assume that the prevalence of ED in Sri Lanka is no different from Western statistics.

\section{Aetiology and pathophysiology}

Contrary to Masters and Johnson and Helen Kaplan who advocated a primarily psychogenic origin for ED, the current understanding is one of a mixed aetiology with either organic or psychological causes predominating. The conditions implicated as risk factors in the aetiology of ED include vasculogenic causes, metabolic syndrome, hormonal causes and benign prostatic hyperplasia [4]. These factors are, discussed further to present the current evidence available.

\section{Vasculogenic causes}

The Princeton consensus (expert panel) conferences (I-III) were convened to address the management of sexual dysfunction in cardiovascular patients. One of its landmark conclusions was that a man with organic ED and no cardiac symptoms or history had an increased cardiovascular disease risk until proven otherwise [5]. The identification of ED in a younger man may confer an $80 \%$ increased risk of coronary artery disease [6].

Common risk factors such as smoking, hypertension, hyperlipidaemia, and diabetes, were identified for coronary artery disease (CAD) and $\mathrm{ED}$, the common pathophysiological event being endothelial dysfunction. The important recommendations of this group included aggressively investigating any ED patient, even without cardiac symptoms, with regards to the possibility of silent heart disease. 


\section{Metabolic syndrome (MetS)}

Epidemiologic studies have demonstrated that the prevalence of MetS has dramatically increased worldwide [7]. The metabolic syndrome which typically includes abdominal obesity, dyslipidemia, hyperglycemia, and hypertension, is an independent risk factor for ED [8]. Identification and correction of the individual factors accounting for this syndrome would help in the management or prevention ofED.

\section{Hormonal causes}

Decreased testosterone hormone levels impact sexual function, in terms of both libido and erectile function. The hormone has been linked to influencing penile nitric oxide synthase, corporeal venous occlusion, penile blood flow and smooth muscle mass in the corpora cavernosa in animal models [9]. Free testosterone levels and bioavailable testosterone levels were found to be inversely correlated with ED while the correlation with total testosterone seems to be clouded by the rise in sex hormone-binding globulin with age [10]. Also several studies have shown the high prevalence of hypogonadotropic hypogonadism in type 2 diabetes [11]. All these factors indicate the importance of assessing for features of testosterone deficiency in patients with ED.

\section{LUTS and BPH}

There is adequate evidence suggesting a strong correlation of lower urinary tract symptoms (LUTS) with ED [12].

The suggested mechanisms which may link these pathologies include an alteration of the nitric oxidecyclic guanosine monophosphate pathway, autonomic hyperactivity and pelvic atherosclerosis among others. Despite this evidence, a recent audit in the UK found that $<10 \%$ of GPs inquired about sexual dysfunction in those presenting with LUTS and offered no treatment to $>80 \%$ though over $90 \%$ of untreated ED patients would have liked to have had medical treatment [13]. The advantages of identifying and pursing the link between these two conditions include the likelihood of finding related co-morbidities and the opportunity to influence outcomes of one condition with the management of the other.

\section{Assessment of patients}

The evaluation of ED patients involves history taking including a focused sexual history, examination and relevant investigation. Despite evidence supporting routine evaluation of patients with regard to sexual dysfunction, physicians tend to neglect this important aspect of clinical evaluation. Some of the factors which may reduce the likelihood of obtaining a sexual history are the lack of time, embarrassment and poor knowledge of sexual dysfunction and its management. [12]

Objective information regarding erectile function can be documented in the clinical setting using the abridged international index of erectile function (IIEF) or IIEF-5 or sexual health inventory for men (SHIM).

Risk factors for Erectile Dysfunction

\begin{tabular}{|l|}
\hline Advancing age \\
\hline Vascular dis orders e.g. cardiovascular disease (hypertension, diabetes mellitus, hyperlipidaemia) \\
\hline Cigare tte s moking \\
\hline Major surgery or radiothe rapy (pelvis or retrope ritone um) \\
\hline $\begin{array}{l}\text { Ne urological dis orde rs (Central or local) } \\
\text { Diabetes mellitus, Parkinson's disease, multiple sclerosis, spinal cord trauma or diseases, stroke, } \\
\text { surgery (pelvis or retroperitoneum) }\end{array}$ \\
\hline $\begin{array}{l}\text { Psychogenic e.g. anxiety, depression, lack of arousability, disorders of sexual intimacy, partner-related } \\
\text { or performance-related issues, sexual trauma or abuse. }\end{array}$ \\
\hline Structural e.g. Peyronie's disease, Hypospadias, congenital curvature of the penis \\
\hline Hormonal disorders e.g. Hypogonadism, hyperprolactinemia, hypothyroidism \\
\hline $\begin{array}{l}\text { Medications e.g. antihypertensives (especially diuretics), benzodiazepines, selective serotonin } \\
\text { reuptake inhibitors antiandrogens, illicit drugs (e.g.marijuana) }\end{array}$ \\
\hline $\begin{array}{l}\text { Trauma e.g. pelvic fractures, penile fracture } \\
\text { Se de ntary lifestyle }\end{array}$ \\
\hline
\end{tabular}


This will give useful information regarding the current status and the response or not to treatment [14]. This has been linguistically validated into both the Sinhala and the Tamil languages [3]. As a surrogate marker, the erection hardness can be measured using the erection hardness grading scale (EHGS) and is useful in the clinical setting to assess the severity of the ED and the response to treatment [15].

With changes in the management protocols in ED, most clinicians would attempt first line treatment before investigating patients extensively with regard to aetiological factors. Any patient should however have a routine fasting glucose or HbAlc and lipid profile [4]. While clinical assessment for features of testosterone deficiency is important, controversy remains regarding the need for testosterone blood levels in all or in select patients. The Princeton consensus panel recommends testing in all patients with organic ED, while the British Society for Sexual Medicine and the International Society for Sexual Medicine recommends testing in all patients with ED. [16]. Further hormonal assays (bioavailable or calculated-free testosterone, serum prolactin), nocturnal penile tumescence and rigidity test, intracavernous injection test, colour duplex doppler ultrasound of the penis, arteriography, dynamic infusion cavernosometry or cavernosography, neurophysiological studies (e.g. bulbocavernosus reflex latency; somatosensory evoked potential test) are requested on a case by case basis only.

\section{Management}

Most patients with ED can be treated successfully with the armamentarium of treatments available. A cure can be attempted only in a few instances e.g. pelvic arterial stenosis due to trauma, endocrine disorders etc. In other patients, a multipronged treatment plan which is goal oriented rather than cause specific, is the currently preferred management option. Options are offered in a stepwise manner, balancing effectiveness, side effects, cost and invasiveness.

Specific psychosexual counselling and treatment is essential in those with predominantly psychogenic ED. However, the concomitant psychological effects of ED on any man needs to be addressed in all patients affected by ED.
Considering the coexistence of risk factors of CAD and ED, life style changes and risk factor modifications take precedence over any specific treatment of ED. These include dietary modifications, regular exercise, abstinence from smoking and weight reduction to achieve a normal BMI.

\section{Oral medication}

This is the first-line treatment without question for most types of ED. Since the introduction of sildenafil in 1998, vardenafil and tadalafil have also been added to the 5-phosphodiesterase inhibitors available for managing ED. Minimal and commonly seen side effects include headache, flushing, dyspepsia and myalgia. These medications are relatively safe in most individuals. Concurrent use with organic nitrates and other nitrate preparations used to treat angina is absolutely contraindicated. Contrary to popular belief there is no increase in myocardial infarction rates with its use. [4]

5PDEIs have been used mainly on an 'on demand' basis. However daily dosing with tadalafil $5 \mathrm{mg}$ has been shown to be well tolerated and effective, and is a useful alternative method of treatment for ED patients who anticipate frequent sexual activity and prefer the spontaneity of sexual activity allowed by daily dosing [17]. Non responders to oral medication at times can be converted to responders with advice regarding the need for adequate sexual stimulation, proper dosage and timing of drug intake, timing of meals, and attempting medication on atleast six occasions prior to discarding a 5PDEI as a failure [18]. Newer preparations such as Avanafil, Udenafil, Lodenafil, and Mirodenafil and Vardenafil - orodispersible tablets, await adequate trials to be established as advantageous over the current oral medications.

The second line of treatment options include vacuum erection devices (VED), intracavernosal injectables, intraurethral instillations and hormone replacement.

\section{Vacuum erection devices (VEDs)}

VEDs containing a vacuum limiter have a useful role especially in ED patients with established, understanding partners. The efficacy may be as high as $90 \%$, however long term compliance with this method of treatment is approximately 50-64\% [19]. Its non-invasiveness and the ability to use it with other

\section{Management of ED}

\begin{tabular}{|ll|}
\hline First line treatment & Life style changes and risk factor modifications, 5-phosphodiesterase inhibitors \\
\hline Second line treatment & Vacuum erection devices (VED), intracavernosal injectables, intraurethral instillations, hormone replacement \\
\hline Third line treatment & Penile prosthesis implantation and other surgical procedures \\
\hline
\end{tabular}


modalities of treatment make it a useful treatment option.

\section{Intracavernosal injectables}

Locally injected vasoactive agents e.g. papaverine, have been used in ED patients since the 1980s. These are especially useful in diabetic patients who are used to self injecting with insulin. Effectiveness and safety has been increased with the introduction of prostaglandins (alprostadil) and the combined use of papaverine, phentolamine and alprostadil e.g trimix. Complications include penile pain, fibrosis, and priapism.

\section{Hormonal treatment}

The young patient with primary hypogonadism will benefit with regard to erectile function with testosterone replacement therapy. In older patients with organic causes of ED, who fail with the above treatment modalities and are found to have low testosterone levels, it is not very clear as to whether testosterone replacement will be of benefit with regards to erectile function The evidence is contradictory. For example, addition of testosterone therapy to 5PDEI treatment in patients with low testosterone levels did not improve the erectile function compared to placebo [20]. However testosterone replacement with long-acting testosterone undecanoate in diabetic patients with low testosterone showed improvements in all domains of the IIEF at 30 weeks and further improvement after a 52-week open-label extension [11]. The Endocrine Society clinical practice guidelines suggest testosterone therapy to those with ED and low testosterone levels following assessment of underlying causes and consideration of other conventional therapies [21]. The consultation of endocrinologists and discussion with patients regarding the long term safety issues of testosterone therapy is therefore sensible prior to starting on testosterone replacement. .

\section{Surgical treatment}

Surgical treatment in ED can be considered under the following categories:

1. Penile prosthesis implantation

2. Vascular surgery

3. Correction of anatomical deformities

\section{Penile prosthesis surgery}

The science and technology behind intracavernosally placed penile prostheses has improved dramatically since their introduction way back in the 1960s [22].
This has led to a reduction in the dreaded complications of infection to $5.3 \%$ [23] and mechanical failure or revision to $12 \%$ at 10 years [24]. Infection rates have been further reduced by the introduction of coated implants (to $2 \%$ ) and the refining of surgical techniques such as the "no touch" technique (reduced to 0.46\%) [23]. Malleable and inflatable types of prostheses are currently used. The preferred method of surgical insertion of these devices is via a penoscrotal incision. The patient and partner feedback with both malleable and inflatable prosthesis indicate that over $90 \%$ of patients / couples are satisfied with the outcome following surgery [25], which makes it the method of treatment with the best outcome in ED management. Our experience in SL with penile prosthesis is limited to small numbers and to the Indian made Shah prosthesis, the main limiting factor of this prosthesis being its poor inherent rigidity [26]. The introduction of standard prostheses to the local surgical sphere would overcome these issues.

\section{Arterial revascularisation surgery}

This is indicated in young patients with demonstrated, isolated arterial stenosis due to trauma. Long term success of these surgical procedures ranges from 60 $70 \%$ [27]. Evidence does not support surgery in the treatment of veno-occlusive ED [28]

\section{Correction of anatomical deformities}

Congenital and acquired curvatures or deformties of the penis (e.g. due to Peyronie's disease) can be cured with surgical intervention. This could be in the form of reconstructive surgery, with or without concomitant penile prosthesis insertion.

\section{ED - looking to the future}

Low-intensity extracorporeal shockwave therapy has been investigated recently with limited though promising results in the treatment of mainly vaculogenic ED. [29-30] The rationale behind its use is that studies have indicated revascularasition of tissue following extracorporeal shockwave therapy in animal models [31-32]. Its potential rehabilitative benefit, make it an exciting area of research for the future.

Alprostadil 0.3\% topical cream (Vitaros) has received licensing rights in Canada and Europe for the treatment of erectile dysfunction. Data from phase III studies showed improved erections in patients who had failed previously on 5PDEIs, with mild to moderate side effects [33].

Molecular research intensively assessing the possibility of 'curing' ED looks at the regenerative 
capabilities of treatment methods. Areas of main focus include 5PDEIs and their ability to increase endothelial progenitor cells (EPCs), gene therapy based mainly on vascular endothelial growth factor (VEGF) gene and nitric oxide synthase (NOS) genes, adipose tissue stem cell and mesenchymal stem cell therapy and RhoA/Rho-kinase signalling pathway in diabetes-associated erectile dysfunction. [34]

\section{Conclusion}

With better understanding of the pathophysiology of ED and the expanding methods of treatment, many patients with ED can be successfully treated. However, a significant limitation in improving management is due to the barriers patients face when seeking help and also in physicians identifying them and / or in offering them treatment. Awareness that ED is a harbinger for cardiovascular disease enables physicians to use this as an early warning sign to better manage patients at risk of cardiovascular disease, metabolic syndrome and other disorders linked by the common denominator of endothelial dysfunction. While definitive treatment is administered, it is important to advice patients regarding life style changes and risk factor modifications and give psychological support.

\section{References}

1.Nair R, Sellaturay S, Sriprasad S. The history of ginseng in the management of erectile dysfunction in ancient China (3500-2600 BCE). Indian J Urol. 2012 Jan-Mar; 28(1): 15-20.

O'Donnell AB

2. Araujo AB, McKinlay JB. The health of normally aging men: The Massachusetts Male Aging Study (1987-2004). Exp Gerontol. 2004 Jul;39(7):97584.

3.Malavige LS, Wijesekara P, Seneviratne Epa D, Ranasinghe P, Levy JC. Ethnic differences in sexual dysfunction among diabetic and nondiabetic males: the Oxford Sexual Dysfunction Study. J Sex Med. 2013 Feb;10(2):500-8

4. Wespes E (chair), Eardley I, Giuliano F, Hatzichristou D, Hatzimouratidis K (vice-chair), Moncada I, Salonia A, Vardi Y. Guidelines on Male Sexual Dysfunction: Erectile dysfunction and premature ejaculation. Uroweb 2013. A v a i 1 a b 1 e a $t$ : http://www.uroweb.org/gls/pdf/14_Male\%20Sex ual\%20Dysfunction_LR.pdf Accessed June 6, 2013.

5.Nehra A, Jackson G, Miner M, Billups KL, Burnett
AL, et al. The Princeton III Consensus Recommendations for the Management of Erectile Dysfunction and Cardiovascular Disease. Mayo Clin Proc. 2012;87(8):766-778

6.Inman BA, St Sauver JL, Jacobson DJ et al. A population-based, longitudinal study of erectile dysfunction and future coronary artery disease. Mayo Clin Proc 2009; 84: 108-13.]

7.Alberti KG, Zimmet P, Shaw J. Metabolic syndrome-a new worldwide definition: a Consensus Statement from the International Diabetes Federation. Diabet Med. 2006;23:469480.

8.Chen K, Mi H, Gao Y, Tan A, Lu Z, Wu C, Liao M, Zhang Y, Mo Z. Metabolic syndrome: a potential and independent risk factor for erectile dysfunction in the Chinese male population. UROLOGY 2012; 80: 1287-1292.

9.Spitzer M, Basaria S, Travison TG, Davda MN, Paley A, Cohen B, Mazer NA et al. Effect of testosterone replacement on response to sildenafil citrate in men with erectile dysfunction: a parallel, randomized trial. Ann Intern Med. 2012 Nov 20;157(10):681-91.

10.Liao M, Huang X, Gao Y, Tan A, Lu Z, et al. (2012) Testosterone Is Associated with Erectile Dysfunction: A Cross-Sectional Study in Chinese Men. PLoS ONE 7 (6): e 39234 . doi:10.1371/journal.pone.0039234

11.Hackett G, Cole N, Bhartia M, Kennedy D, Raju J, and Wilkinson P. Testosterone replacement therapy with long-acting Testosterone Undecanoate improves sexual function and quality-of-life parameters vs. placebo in a population of men with type 2 diabetes. J Sex Med 2013;10:1612-1627

12.Kirby M, Chapple C, Jackson G, Eardley I, Edwards D, Hackett G, Ralph D, Rees J, Speakman M, Spinks J, Wylie K. Erectile dysfunction and lower urinary tract symptoms: a consensus on the importance of co-diagnosis. Int J Clin Pract. 2013 Jul;67(7):606-18.

13.Chitale S, Collins R, Hull S, Smith E, Irving S. Is the current practice providing an integrated approach to the management of LUTS and ED in primary care? An audit and literature review. J Sex Med 2007; 4: 1713-25.

14.Rosen RC, Cappelleri JC, Smith MD, Lipsky J, Pena BM. Development and evaluation of an abridged, 5-item version of the International Index of Erectile Function (IIEF-5) as a diagnostic tool for erectile dysfunction. Int $J$ Impot Res 1999;11:319-26.

15.Rosen RC, Althof SE, Giuliano F. Research 
instruments for the diagnosis and treatment of patients with erectile dysfunction. Urology 2006; 68 (Suppl3A): 6-16.

16.Nehra A, Jackson G, Miner M, et al. The Princeton III Consensus Recommendations for the management of erectile dysfunction and cardiovascular disease. Mayo Clin Proc. 2012;87(8):766-778.

17.Porst H, Rajfer J, Casabé A, Feldman R, Ralph D, Vieiralves LF, Esler A, Wolka AM, and Klise SR. Long-term safety and efficacy of tadalafil $5 \mathrm{mg}$ dosed once daily in men with erectile dysfunction. J Sex Med 2008;5:2160-2169.

18.Rajagopalan P, Mazzu A, Xia C, et al. Effect of high-fat breakfast and moderate-fat evening meal on the pharmacokinetics of vardenafil, an oral phosphodiesterase- 5 inhibitor for the treatment of erectile dysfunction. J Clin Pharmacol 2003 Mar;43(3):260-7

19.Cookson MS, Nadig PW. Long-term results with vacuum constriction device. J Urol 1993 Feb;149(2):290-4.

20, Spitzer M,Basaria S, Travison TG, Davda MN, Paley A, Cohen B, et al. Effect of testosterone replacement on response to sildenafil citrate in men with erectile dysfunction: a parallel, randomized trial. Ann Intern Med. 2012;157:681-691.

21.Bhasin S, Cunningham GR, Hayes FJ, et al. Testosterone therapy in men with androgen deficiency syndromes: an Endocrine Society clinical practice guideline. J Clin Endocrinol Metab. 2010;95(6):2536-2559.

22.Henry GD. Historical review of penile prosthesis design and surgical techniques: Part 1 of a threepart review series on penile prosthetic surgery. J Sex Med 2009;6:675-681.

23.Eid JF, Wilson SK, Cleves M, Salem EA. Coated implants and "no touch" surgical technique decreases risk of infection in inflatable penile prosthesis implantation to $0.46 \%$. Urology. 2012 Jun;79(6):1310-5

24.Wilson SK, Delk JR, Salem EA, and Cleves MA. Penile prostheses: Single surgical group experience with 2,384 first-time implants spanning two decades. J Sex Med 2007;4:1074-1079.

25.Montorsi F, Rigatti P, Carmignani G, et al. AMS three-piece inflatable implants for erectile dysfunction: a long-term multi- institutional study in 200 consecutive patients. Eur Urol 2000 Jan;37(1):50-5.

26.Malalasekera AP, Jayasundare JMNRK, Perera ND. Penile prosthesis surgery for erectile dysfunction - a viable option for Sri Lankan patients. Presentation at the Annual Scientific Sessions of the College of Surgeons of Sri Lanka, 2010.

27.Rao DS, Donatucci CF. Vasculogenic impotence. Arterial and venous surgery. Urol Clin North Am 2001 May;28(2):309-19

28. Montague DK, Jarow JP, Broderick GA, Dmochowski RR, Heaton JP, Lue TF, Milbank AJ, Nehra A, Sharlip ID; Erectile Dysfunction Guideline Update Panel. Chapter 1: The management of erectile dysfunction: an AUA update.J Urol. $2005 \mathrm{Jul} ; 174(1)$ :230-9.

29. Vardi Y, Appel B, Jacob G, Massarwi O, Gruenwald I. Can Low-Intensity Extracorporeal Shockwave Therapy Improve Erectile Function? A 6-Month Follow-up Pilot Study in Patients with Organic Erectile Dysfunction. Eur Urol 58 (2010) 243-248.

30.Vardi Y, Appel B, Kilchevsky A, Gruenwald I. Does low intensity extracorporeal shock wave therapy have a physiological effect on erectile function? Short-term results of a randomized, double-blind, sham controlled study. J Urol. 2012 May;187(5):1769-75.

31.Nishida T, Shimokawa H, Oi $K$, et al. Extracorporeal cardiac shock wave therapy markedly ameliorates ischemia-induced myocardial dysfunction in pigs in vivo. Circulation 2004; 110:3055-61.

32.Wang C-J, Wang F-S, Yang KD, Weng L-H, Huang C-S, Yang L-C. Shock wave therapy induces neovascularization at the tendonbone junction: a study in rabbits. J Orthop Surg 2003;21:984-9.

33Mulhall J, Buvat J, Goldstein I, Damaj B, Frank D, Fernando Y. Vitarosâ efficacy and safety in Viagra non-responders with longer term use. Poster presentation at the American Urological Association Annual Meeting, 2013.

34.R. A. Condorelli, A. E. Calogero, E. Vicari, V. Favilla, G. Morgia, S. Cimino and S. La Vignera. Vascular regenerative therapies for the treatment of erectile dysfunction: current approaches. Andrology, 2013, 1, 533-540 